\title{
Mechanisms of Sound Localization in Two Functionally Distinct Regions of the Auditory Cortex
}

\author{
Khaleel A. Razak, Stuart Yarrow, and Dustin Brewton \\ Department of Psychology, University of California, Riverside, Riverside, California 92521
}

The auditory cortex is necessary for sound localization. The mechanisms that shape bicoordinate spatial representation in the auditory cortex remain unclear. Here, we addressed this issue by quantifying spatial receptive fields (SRFs) in two functionally distinct cortical regions in the pallid bat. The pallid bat uses echolocation for obstacle avoidance and listens to prey-generated noise to localize prey. Its cortex contains two segregated regions of response selectivity that serve echolocation and localization of prey-generated noise. The main aim of this study was to compare 2D SRFs between neurons in the noise-selective region (NSR) and the echolocation region [frequencymodulated sweep-selective region (FMSR)]. The data reveal the following major differences between these two regions: (1) compared with NSR neurons, SRF properties of FMSR neurons were more strongly dependent on sound level; (2) as a population, NSR neurons represent a broad region of contralateral space, while FMSR selectivity was focused near the midline at sound levels near threshold and expanded considerably with increasing sound levels; and (3) the SRF size and centroid elevation were correlated with the characteristic frequency in the NSR, but not the FMSR. These data suggest different mechanisms of sound localization for two different behaviors. Previously, we reported that azimuth is represented by predictable changes in the extent of activated cortex. The present data indicate how elevation constrains this activity pattern. These data suggest a novel model for bicoordinate spatial representation that is based on the extent of activated cortex resulting from the overlap of binaural and tonotopic maps.

Key words: auditory cortex; spatial processing; sound localization; binaural cues; elevation coding; spectral cues

Significance Statement

Unlike the visual and somatosensory systems, spatial information is not directly represented at the sensory receptor epithelium in the auditory system. Spatial locations are computed by integrating neural binaural properties and frequency-dependent pinna filtering, providing a useful model to study how neural properties and peripheral structures are adapted for sensory encoding. Although auditory cortex is necessary for sound localization, our understanding of how the cortex represents space remains rudimentary. Here we show that two functionally distinct regions of the pallid bat auditory cortex represent 2D space using different mechanisms. In addition, we suggest a novel hypothesis on how the nature of overlap between systematic maps of binaural and frequency selectivity leads to representation of both azimuth and elevation.

\section{Introduction}

The auditory cortex is required for sound localization in both azimuth (Whitfield et al., 1972; Jenkins and Merzenich, 1984; Kavanagh and Kelly, 1987; Heffner, 1997; Malhotra et al., 2004) and elevation (Bizley et al., 2007). Most studies of cortical spatial encoding have focused on binaural and azimuth selectivity. The

\footnotetext{
Received July 6, 2015; revised Oct. 21, 2015; accepted 0ct. 28, 2015.

Author contributions: K.A.R. and D.B. designed research; K.A.R. and D.B. performed research; K.A.R., S.Y., and D.B. analyzed data; K.A.R. and D.B. wrote the paper.

This study was funded by the National Science Foundation (Grant IOS 1252769). We thank Dr. Zoltan Fuzessery and Dr. Len Kitzes for useful discussions of the data and comments on an earlier version of this manuscript.

The authors declare no competing financial interests.

Correspondence should be addressed to Khaleel Razak, Department of Psychology, University of California, 900 University Avenue, Riverside, CA 92521. E-mail: khaleel@ucr.edu.

DOI:10.1523/JNEUROSCI.2563-15.2015

Copyright $\odot 2015$ the authors $\quad 0270-6474 / 15 / 3516105-11 \$ 15.00 / 0$
}

lack of a "one-to-one" space map in the cortex and the relatively broad tuning of neurons that can expand further with sound level have led to suggestions that population activity patterns represent azimuth locations (Middlebrooks and Pettigrew, 1981; Rajan et al., 1990b; Nakamoto et al., 2004; Stecker et al., 2005; King et al., 2007). The nature of such population codes is only beginning to be understood (Miller and Recanzone, 2009; Razak, 2011). Relatively little is known about how source elevation is represented (Xu et al., 1998; Reale et al., 2003; Mrsic-Flogel et al., 2005), resulting in a lack of models to explain 2D spatial encoding in auditory cortex. The present study addressed this issue by recording spatial receptive fields (SRFs) of neurons in two functionally distinct regions of the auditory cortex.

The subject of this study was the pallid bat (Antrozous pallidus), a species that localizes and hunts terrestrial prey (e.g., crickets, scorpions) by listening to prey-generated noise (e.g., walking, rustling, at 
5-40 kHz), while reserving echolocation with downward frequency-modulated (FM) sweeps (60 $\rightarrow 30 \mathrm{kHz}, 2-5 \mathrm{~ms}$ ) for orientation and obstacle avoidance (Bell, 1982; Barber et al., 2003). The colliculusthalamus-cortex connections are organized as parallel pathways with segregated selectivity for noise and downward FM sweeps (Fuzessery, 1994; Razak and Fuzessery, 2002; Razak et al., 2007). In the auditory cortex, neurons are segregated into two regions with properties that suggest involvement in prey localization [noise-selective region (NSR)] and echolocation [FM sweep-selective region (FMSR)]. The two cortical regions receive inputs from distinct thalamic areas, with the dorsal division of medial geniculate body (MGB) projecting to the FMSR, and ventral MGB projecting to the NSR (Razak et al., 2007). The presence of functionally segregated pathways provides the opportunity to compare sound localization mechanisms that underlie two different behaviors.

A previous mapping study of the NSR showed that a systematic change in the extent of activated auditory cortex represents azimuth (Razak, 2011). The NSR contains two distinct binaural clusters. One cluster of neurons responds best to interaural level differences (ILDs) near $0 \mathrm{~dB}$ and to $0-15^{\circ}$ azimuth, providing a spatial acoustic fovea for midline locations (Razak and Fuzessery, 2010; Razak, 2011). The second cluster contains binaurally inhibited (EI) neurons with a systematic map of ILD selectivity (Razak and Fuzessery, 2002). The ILD at which the response is inhibited is arranged systematically within the EI cluster. This results in azimuthdependent systematic changes in the extent of activated cortex (Razak, 2011) in a manner similar to that proposed in the superior (Wise and Irvine, 1985) and inferior colliculi (Fuzessery et al., 1985). How the elevation of the sound source influences this azimuthdependent activity map in the EI cluster is not known and forms a major aim of this study. For this purpose, 2D SRFs of EI cluster neurons were characterized.

The FMSR neurons are selective for downward FM sweeps with sweep rates present in the echolocation calls of the pallid bat. These neurons respond poorly or not at all to upward sweeps, noise, and pure tones. Unlike the NSR, in which nearly $85 \%$ of neurons are ILD selective, nearly $65 \%$ of FMSR neurons are insensitive to ILDs (Razak and Fuzessery, 2002). To identify the consequence of differential binaural selectivity in the NSR and the FMSR to free-field spatial encoding, the SRFs of FMSR neurons were also characterized. The data indicate a significant correlation between elevation properties of the SRF and the characteristic frequencies (CFs) of NSR neurons. This indicates that the ILD/azimuth-dependent extent of cortical activity will be constrained by elevation-frequency relationships providing a novel hypothesis for cortical representation of 2D space that depends on overlapping ILD and tonotopic maps.

\section{Materials and Methods}

Pallid bats were netted in Arizona, New Mexico, and California, and were held in a $11 \times 14$ foot room at the University of California, Riverside. The bats were able to fly in this room and were provided crickets/mealworms and water ad libitum. The room was maintained on a reversed $12 \mathrm{~h}$ light/dark cycle. All procedures followed the animal welfare guidelines required by the National Institutes of Health and the Institutional Animal Care and Use Committee.

Surgical procedures. Recordings were obtained from adult pallid bats $(n=14)$ anesthetized with isoflurane inhalation, followed by an intraperitoneal injection of pentobarbital sodium ( $30 \mu \mathrm{g} / \mathrm{g}$ body weight $)$ and acepromazine ( $2 \mu \mathrm{g} / \mathrm{g}$ body weight). Both male and female bats were used. The surgical and recording procedures were as described in detail in previous articles (Razak and Fuzessery, 2002; Razak, 2011). Briefly, to expose the auditory cortex, the head was held in a bite bar, a midline incision was made in the scalp, and the muscles over the dorsal surface of the skull were reflected to the sides. The bat was placed in a Plexiglas holder. A cylindrical aluminum head pin was inserted through a crossbar over the head of the bat and was cemented to the front of the skull. This pin served to hold the head of the bat securely during the recording session. The location of $\mathrm{A} 1$ was determined relative to the rostrocaudal extent of the midsagittal sinus, the distance laterally from the midsagittal sinus, and the location of a prominent lateral blood vessel that travels parallel to the midsagittal sinus (Razak and Fuzessery, 2002). The size of the exposure was $\sim 2 \mathrm{~mm}^{2}$. The exposed brain surface was covered with paraffin oil to prevent desiccation.

Recording and stimulus protocols. Experiments were conducted in a warm $\left(\sim 80^{\circ} \mathrm{F}\right)$ sound attenuation room lined with anechoic foam (Gretch-Ken Industries). All recordings were obtained from the right hemisphere. Bats were kept anesthetized throughout the course of the experiments with additional pentobarbital sodium injections. Acoustic stimulation and data acquisition were driven by custom-written software (Batlab, Dr. Don Gans, Kent State University, Kent, OH) and a Microstar digital signal processing (DSP) board. Programmable attenuators (PA5, Tucker-Davis Technologies) allowed the control of sound levels before amplification by a stereo power amplifier (HCA1100, Parasound; or AX430, Yamaha). Extracellular single-unit recordings were obtained using glass electrodes ( $1 \mathrm{M} \mathrm{NaCl}, 2-10 \mathrm{M} \Omega$ impedance) at depths between 200 and $600 \mu \mathrm{m}$. The pallid bat auditory cortex is $\sim 800 \mu \mathrm{m}$ thick from pia to white matter. Cortical layer IV/V boundary lies at $\sim 55 \%$ from the pia (Martin del Campo et al., 2014). Layer V begins $\sim 450 \mu \mathrm{m}$ from the 


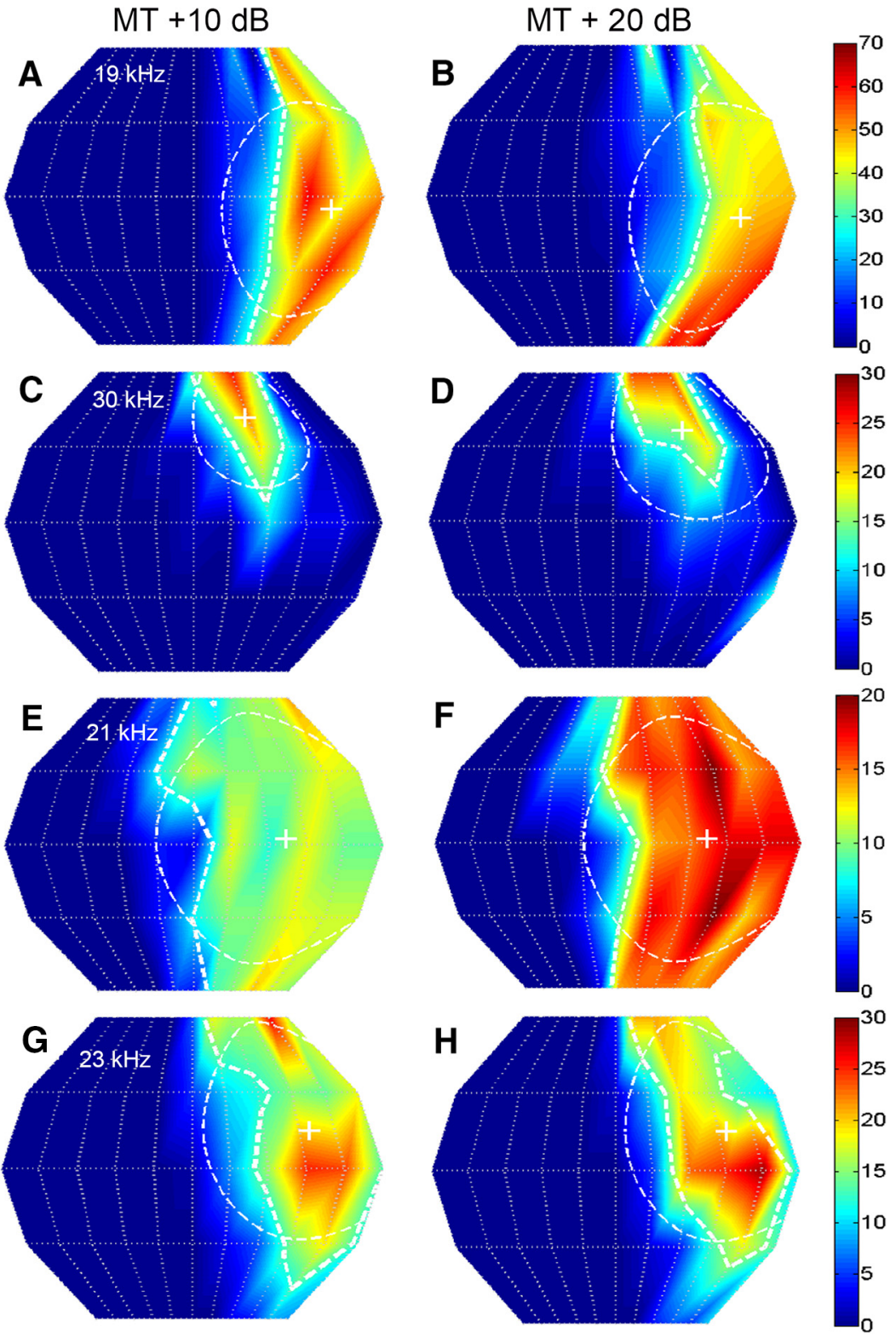

Figure 2. The SRF properties of NSR neurons were stable with sound level. Each panel shows the 2D SRF of a NSR neuron. Left column, Responses were calculated for noise presented at MT $+10 \mathrm{~dB}$. Right column, Responses from the same neuron shown to the left, but measured at $\mathrm{MT}+20 \mathrm{~dB}$. The response magnitude color chart is shown to the right of each neuron and corresponds to both the MT $+10 \mathrm{~dB}$ and MT $+20 \mathrm{~dB}$ plots. $A, B$, Neuron \#41B05, $C F=19 \mathrm{kHz}$; the centroid azimuth at MT $+10 \mathrm{~dB}$ and MT $+20 \mathrm{~dB}$ was $54^{\circ}$ and $53^{\circ}$, respectively. The centroid elevation at the two sound levels was $-5^{\circ}$ and $-9^{\circ}$. The gyradii at the two different sound levels were $44^{\circ}$ and $46^{\circ}$. C, D, Neuron \#70CO2; $\mathrm{CF}=30 \mathrm{kHz}$; centroid azimuth $=28^{\circ} ; 35^{\circ}$; centroid elevation $=$ $42^{\circ}, 37^{\circ}$; gyradius $=28^{\circ}, 36^{\circ} . \mathbf{E}, \boldsymbol{F}$, Neuron \#83A01; CF $=21 \mathrm{kHz}$; centroid azimuth $=36^{\circ}, 36^{\circ} ;$ centroid elevation $=3^{\circ}, 2^{\circ}$; gyradius $=51^{\circ}, 50^{\circ} . \mathbf{G}, \mathbf{H}$, Neuron $\# 78 \mathrm{BO} 3 ; \mathrm{CF}=23 \mathrm{kHz}$; centroid azimuth $=47^{\circ}, 48^{\circ}$; centroid elevation $=15^{\circ}, 15^{\circ} ;$ gyradius $=$ $43^{\circ}, 43^{\circ}$.

pia. The recordings, therefore, include neurons from primarily cortical layers III, IV, and V. Penetrations were made orthogonal to the surface of the cortex. Action potentials were amplified by a Dagan extracellular preamplifier (2400A) and a spike signal enhancer (FHC) and bandpass filtered $(0.3-3 \mathrm{kHz}$; Krohn-Hite). Waveforms and peristimulus time histograms were stored. All data shown are from single-unit recordings identified by the consistency of action potential amplitude and waveform displayed on an oscilloscope. Responses were quantified as the total number of spikes elicited by 20 stimulus presentations at a $1 \mathrm{~Hz}$ repetition rate.

The main goal of this study was to determine the 2D SRF of NSR and FMSR neurons. Free-field stimulation was achieved with an LCY-K100 speaker that was moved manually to different locations $\left[75^{\circ}\right.$ contralat- eral (CL) to $75^{\circ}$ ipsilateral (IL) in azimuth, $15^{\circ}$ resolution] on a semicircular loop $(40 \mathrm{~cm}$ radius with the head of the bat as the center). The loop was mounted on a vibration isolation table (TMC). The loop could be rotated into one of five elevation positions $\left(60^{\circ}\right.$ below to $60^{\circ}$ above the head of the bat, $30^{\circ}$ resolution). Thus, up to 55 spatial locations ( 11 horizontal $\times 5$ vertical) were tested for each neuron to generate the SRF. The amplifier-speaker frequency response curve measured with a 0.25 inch microphone (Bruel and Kjaer) was flat within $\pm 3 \mathrm{~dB}$ for frequencies from 8 to $35 \mathrm{kHz}$. The rolloff from 35 to $80 \mathrm{kHz}$ was gradual at a rate $\sim 20 \mathrm{~dB}$ /octave. The bat was placed on the edge of the table such that its head was at the center of the loop. The snout of the bat faced $0^{\circ}$ azimuth/elevation. The crossbar holding the head pin was secured behind the bat, leaving no interference between the free-field speaker and the head of the bat.

Stimuli used for 2D SRF measurements. For SRF measurements, behaviorally relevant sounds appropriate for each region were used. The NSR and FMSR are segregated regions in the pallid bat auditory cortex with the NSR located caudolateral to the FMSR (Razak and Fuzessery, 2002). Although these regions occupy a single continuous tonotopic map from $\sim 7$ to $70 \mathrm{kHz}$, the NSR receives input from the ventral MGB, while the FMSR receives input primarily from the suprageniculate nucleus of the dorsal MGB (Razak et al., 2007). The two regions are also distinguished by response selectivity (Razak and Fuzessery, 2002, 2006, 2008, 2009, 2010; Razak, 2011). The CFs in the NSR range between 7 and $35 \mathrm{kHz}$ and most NSR neurons respond better to broadband noise with a bandwidth between 5 and $40 \mathrm{kHz}$ over narrowband noise or tones. Based on similarities in response properties such as short latency, narrow tuning, and tonotopy, and inputs from the ventral MGB, the NSR is the primary auditory cortex in the pallid bat. The CFs in the FMSR range between 25 and $65 \mathrm{kHz}$ and most neurons respond best or exclusively to downward FM sweep with sweep rates that mimic the echolocation call of the bat compared with upward FM sweeps, noise, and tones. Thus, the FMSR and NSR are part of functionally distinct pathways.

The NSR contains two clusters of neurons distinguished by ILD selectivity (Razak and Fuzessery, 2002, 2010; Razak, 2011, 2012). A cluster of EI neurons is located caudal to a peaked neuron cluster. The EI neurons respond monaurally only to CL ear stimulation. Under binaural stimulation, increasing the IL ear sound level causes the inhibition of response. These neurons are also classified as EO/I in the literature. The peaked neurons can be classified as predominantly binaural or OO/FI - neurons that do not respond to monaural stimulation of either ear, but are facilitated by binaural input and inhibited when ipsilateral intensity is increased further. Binaural stimulation with ILD near $0 \mathrm{~dB}$ produces a maximum response, and further increases in IL sound level cause inhibition. Almost all peaked neurons respond best to stimuli located between $-15^{\circ}$ and $+15^{\circ}$ azimuth and poorly to the lateral locations. All EI neurons respond best to broadband noise presented in CL azimuth locations (Razak, 2011). Because the main goal here was to determine how elevation constrains cortical activity spread within the EI 
cluster, we focused on measuring SRFs only for the EI neurons. To isolate neurons in the EI cluster of the NSR, broadband noise (5-40 $\mathrm{kHz}, 5-10 \mathrm{~ms}$ duration, 20-70 dB SPL) was presented either from CL $15^{\circ}$ or $60^{\circ}$ azimuth locations. An EI neuron that responds to the $15^{\circ}$ location will also respond to the $60^{\circ}$ location (Razak, 2011, 2012). Neurons that responded only to the $60^{\circ}$ location, but not the $15^{\circ}$ location, are also of the EI type. If a neuron responded only to the $15^{\circ}$ location, but not the $60^{\circ}$ location, it was not studied further because this is a characteristic of peaked neurons. This method allowed us to focus on EI neurons.

Once an EI neuron was isolated, the first step was to qualitatively determine the best azimuth position for broadband noise by moving the speaker between $-15^{\circ}$ and $+75^{\circ}$ locations with $15^{\circ}$ resolution. With the speaker at the optimal azimuth location, the $\mathrm{CF}$ of the neuron was determined as the tone frequency $(5-40 \mathrm{kHz}, 5$ kHz steps, 20-70 dB SPL, 5-10 ms duration, 1 $\mathrm{ms}$ rise/fall time, $1 \mathrm{~Hz}$ repetition rate) that elicited responses to at least five successive presentations at the lowest sound level tested. The minimum threshold (MT) for noise was determined by increasing the SPL from 20 to $70 \mathrm{~dB}$ ( $5 \mathrm{~dB}$ steps to start and $1 \mathrm{~dB}$ steps closer to threshold) and noting the lowest SPL that elicited responses to at least five successive presentations. Following this, the response of the neuron to broadband noise $(10 \mathrm{~dB}$ above threshold) was recorded with the speaker at different azimuth $\left(+75^{\circ}\right.$ to $-75^{\circ} \mathrm{IL}, 15^{\circ}$ resolution) and elevation $\left(60^{\circ}\right.$ up to $60^{\circ}$ down, $30^{\circ}$ resolution) locations.

For the majority of NSR neurons studied ( 81 of 104 neurons), a second sound level (15-30 $\mathrm{dB}$ above MT) was also tested at each location to determine the level stability of SRF properties. Although this is a moderate range of sound levels, it must be noted that the pallid bats hunt by listening to sounds generated by the movement of small insects. Therefore, the range of behaviorally relevant sound levels is not large. For example, the steps of an $\sim 1$ g (body weight) scorpion on desert soil produce sound levels 55-60 dB peak equivalent SPL (at 10 cm distance; Holderied et al., 2011). Pallid bats forage at heights between 0.5 and $2.5 \mathrm{~m}$ from the ground (O'Shea and Vaughan, 1977). From the ground to up to $3 \mathrm{~m}$ height, the range of sound levels of prey-generated noise is unlikely to be $>20 \mathrm{~dB}$ SPL (between $\sim 40$ and $60 \mathrm{~dB}$ SPL). Other prey of the pallid bat such as crickets and beetles weigh $<1 \mathrm{~g}$ and will produce a smaller range of SPL variation. Therefore, the sound levels used here to study stability likely fall in the behaviorally relevant range.

To isolate single-neuron responses in the FMSR, search stimuli were presented from the free-field speaker positioned at $0^{\circ}$ azimuth and elevation (to mimic echoes along the flight path). The search stimuli used were linear downward $60 \rightarrow 30 \mathrm{kHz}$ or $70 \rightarrow 20 \mathrm{kHz}$ FM sweeps $(2-5 \mathrm{~ms}$ duration, levels between 0 and $70 \mathrm{~dB}$ SPL, $1 \mathrm{~Hz}$ repetition rate, $1 \mathrm{~ms}$ rise/fall time). Upon isolation of a neuron, the CF was determined by presenting tones (5-10 ms duration, $1 \mathrm{~ms}$ rise/fall times, $1 \mathrm{~Hz}$ repetition rate) with frequencies between 25 and $70 \mathrm{kHz}$ ( 1 or $5 \mathrm{kHz}$ step) and levels between 0 and $70 \mathrm{~dB}$ SPL ( $5 \mathrm{~dB}$ step). The free-field speaker was still at $0^{\circ}$ azimuth/elevation for $\mathrm{CF}$ determination. The $\mathrm{CF}$ was the tone frequency, or the center of the tone frequency range, that elicited action potentials to
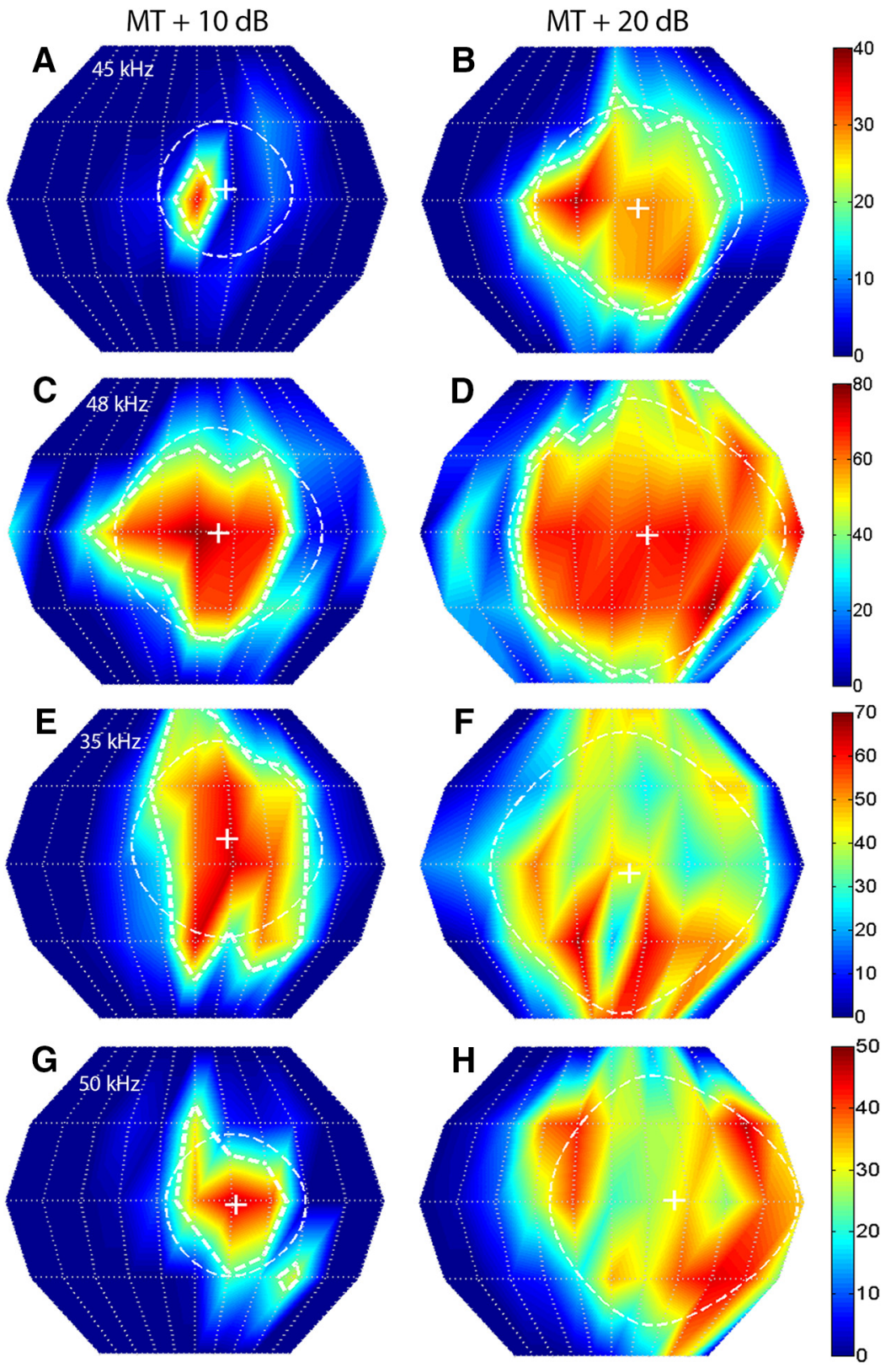

Figure 3. The SRF properties of FMSR neurons were strongly sound level dependent. The left and right columns correspond to SRFs recorded from the same FMSR neurons, but at MT $+10 \mathrm{~dB}$ and MT $+20 \mathrm{~dB}$, respectively. The $50 \%$ SRF contours are not shown for neurons in $\boldsymbol{E}-\boldsymbol{H}$ because of the fragmenting of the SRF into multiple peaks at the higher SPL. $\boldsymbol{A}, \boldsymbol{B}$, Neuron \#96A01; CF $=$ $45 \mathrm{kHz}$; centroid azimuth $=11^{\circ}, 9^{\circ}$; centroid elevation $=4^{\circ},-3^{\circ}$; gyradius $=26^{\circ}, 40^{\circ}$. C, D, Neuron \#77A02; CF $=48 \mathrm{kHz}$ centroid azimuth $=9^{\circ}, 14^{\circ}$; centroid elevation $=-1^{\circ},-1^{\circ}$; gyradius $=41^{\circ}, 54^{\circ} . \boldsymbol{E}, \boldsymbol{F}$, Neuron \#36A04; $\mathrm{CF}=35 \mathrm{kHz}$; centroid azimuth $=13^{\circ}, 7^{\circ}$; centroid elevation $=10^{\circ},-3^{\circ} ;$ gyradius $=38^{\circ}, 54^{\circ} . \mathbf{G}, \boldsymbol{H}$, Neuron \#86B03; $\mathrm{CF}=50 \mathrm{kHz}$; centroid azimuth $=$ $16^{\circ}, 24^{\circ}$; centroid elevation $=-2^{\circ}, 1^{\circ} ;$ gyradius $=28^{\circ}, 48^{\circ}$.

at least five successive stimulus repetitions at the lowest sound level tested. After identifying the CF, a downward FM sweep with the CF as the approximate center frequency, duration between 2 and $5 \mathrm{~ms}$, and bandwidths between 20 and $40 \mathrm{kHz}$ (to optimize sweep rate) was used as a stimulus to record MT for FM sweep and SRF. The duration (range, 2-5 $\mathrm{ms}$; resolution, $1 \mathrm{~ms}$ ) and bandwidth (range, $20-40 \mathrm{kHz}$; resolution, 10 $\mathrm{kHz}$ ) were changed to qualitatively and quickly identify the sweep that produced robust responses while still approximating the natural echolocation call. This stimulus is referred to as the optimal FM sweep. To identify the MT of the FMSR neuron, the speaker was positioned at $0^{\circ}$ azimuth/elevation, and the optimal FM sweep was presented with increasing levels between 0 and $70 \mathrm{~dB}$ SPL ( $5 \mathrm{~dB}$ steps to start and $1 \mathrm{~dB}$ steps closer to threshold). The MT was defined as the lowest sound level to 


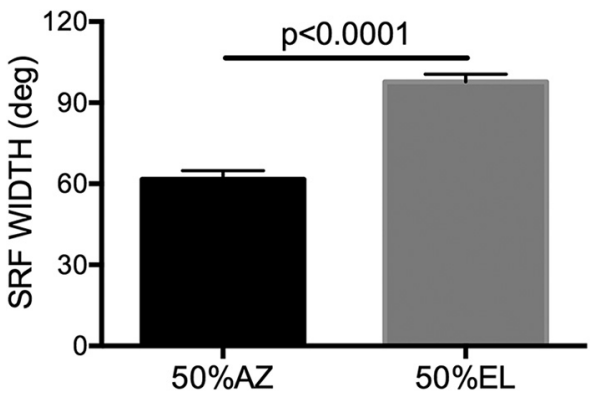

Figure 4. SRFs of NSR neurons were larger in elevation than azimuth. The $50 \%$ SRF is the width of the SRF, inside of which the response was within $50 \%$ of the maximum. The $50 \%$ SRF-AZ and 50\%SRF-EL were calculated as the SRF width, with the centroid as reference. A paired $t$ test revealed a significant difference.

which the neuron responded to at least five successive presentations. To record SRFs, the optimal FM sweep was presented at $10 \mathrm{~dB}$ above threshold from up to 55 speaker locations. In the majority of FMSR neurons ( 48 of 55 neurons), SRF was also determined at a second sound level (15-30 $\mathrm{dB}$ above MT) to determine the level stability of FMSR neurons.

Quantification of SRF properties. The SRFs were plotted and analyzed using code written in MATLAB. The SRFs were quantified using three of their geometrical properties: the centroid, the 50\% SRF, and the polar radius of gyration (gyradius). The centroid and gyradius can be understood by considering a physical analogy. The SRF can be thought of as a large mountain on the surface of a globe, where the response firing rate is equivalent to surface elevation, azimuth is equivalent to longitude, and elevation is equivalent to latitude. The centroid of the SRF is equivalent to the position (latitude and longitude) of the center of gravity of the mountain. To understand the gyradius, consider the globe rotating about an

A

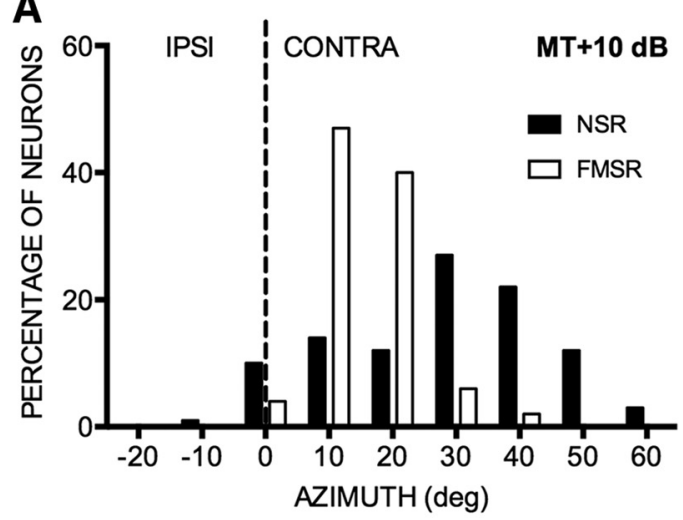

C

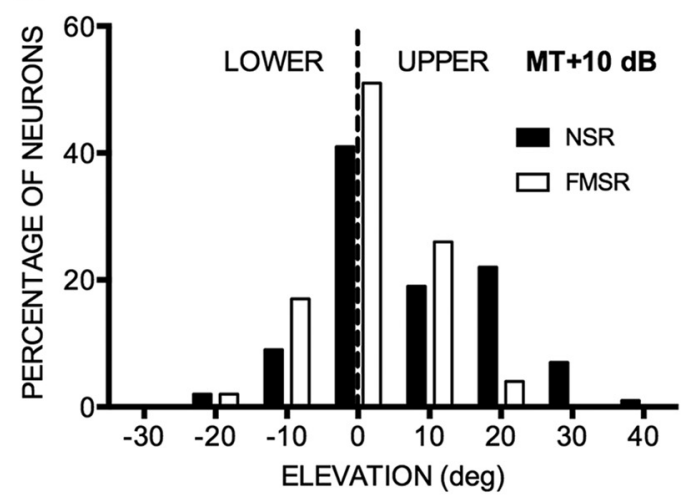

axis that passes through the center of gravity of the mountain. If the mass of the mountain is distributed far from the axis, it will have greater rotational inertia than if the mass is concentrated close to the axis. If the entire mass of the mountain is concentrated at a single point, the gyradius quantifies the distance that this point must be from the axis of rotation to maintain the same rotational inertia. Thus, the gyradius of the SRF quantifies the angular size of the SRF in a way that takes the entire response into account and is not sensitive to the level of activity in any particular region of the SRF.

Each SRF was defined by $N$ data, each of which was composed of measurements of azimuth ( $\varphi_{i}$ for the $i$ th datum), elevation $\left(\theta_{i}\right)$, and response spike count $\left(r_{i}\right)$. The centroid of the SRF was found by taking moments about the origin; this discounts the circular nature of the azimuth dimension, but does not result in loss of accuracy as all data were located in the frontal hemisphere. The azimuth of the centroid was defined as follows:

$$
\varphi_{\text {centroid }}=\frac{\sum \varphi_{i} r_{i}}{\sum r_{i}},
$$

and the elevation of the centroid as follows:

$$
\theta_{\text {centroid }}=\frac{\sum \theta_{i} r_{i}}{\sum r_{i}} .
$$

To find the gyradius about the centroid, we first needed to find the total angle between the centroid and each datum. Total angle was given by the law of cosines, as follows:

$\phi_{i}=\arccos \left(\sin \left(\theta_{\text {centroid }}\right) \sin \left(\theta_{i}\right)+\cos \left(\theta_{\text {centroid }}\right) \cos \left(\theta_{i}\right)\right.$

$$
\left.\times \cos \left(\varphi_{\text {centroid }}-\varphi_{i}\right)\right) .
$$

\section{B}

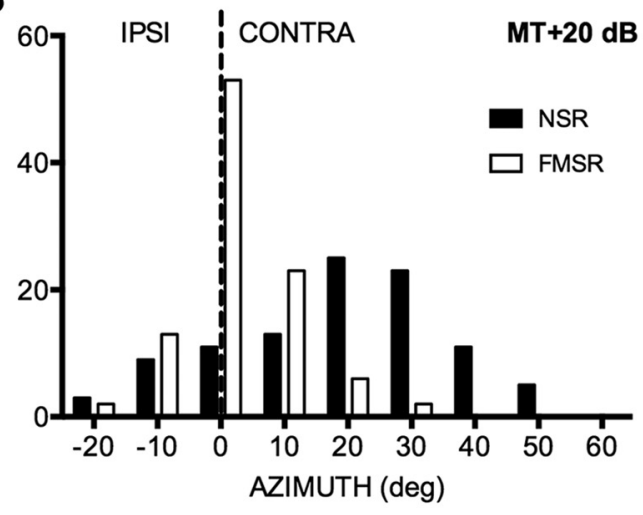

D

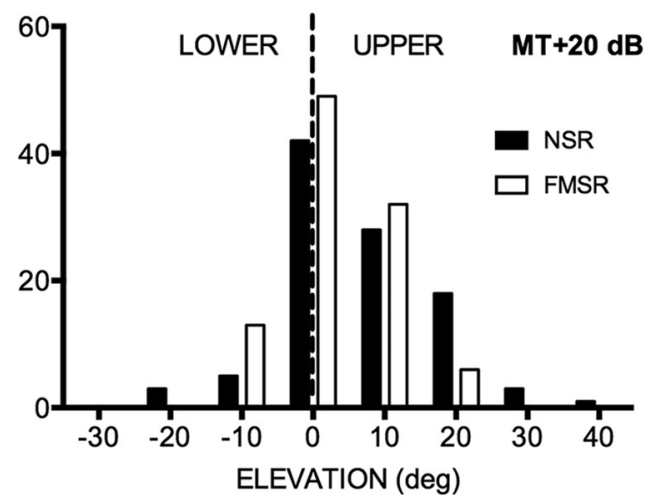

Figure 5. Across the population, NSR neuron centroids were more broadly distributed in 2D space compared with FMSR neurons. $A, B$, Distribution of centroid azimuths in FMSRs and NSRs recorded at $10 \mathrm{~dB}(\boldsymbol{A})$ and $20 \mathrm{~dB}(\boldsymbol{B})$ above threshold. $\boldsymbol{C}, \boldsymbol{D}$, The distribution of centroid elevation in FMSRs and NSRs recorded at $10 \mathrm{~dB}(\boldsymbol{C})$ and $20 \mathrm{~dB}(\boldsymbol{D})$ above threshold. The dashed lines in $\boldsymbol{A}$ and $\boldsymbol{B}$ demarcate ipsilateral (IPSI) and contralateral (CONTRA) azimuth locations. The dashed lines in $\boldsymbol{C}$ and $\mathbf{D}$ demarcate the upper and lower elevations. 


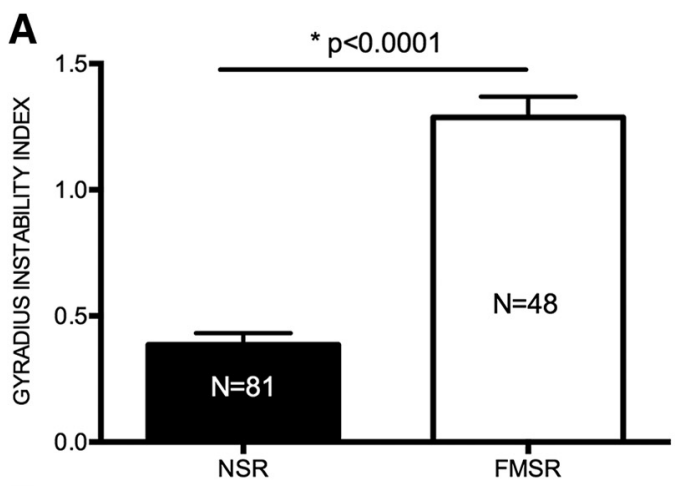

B
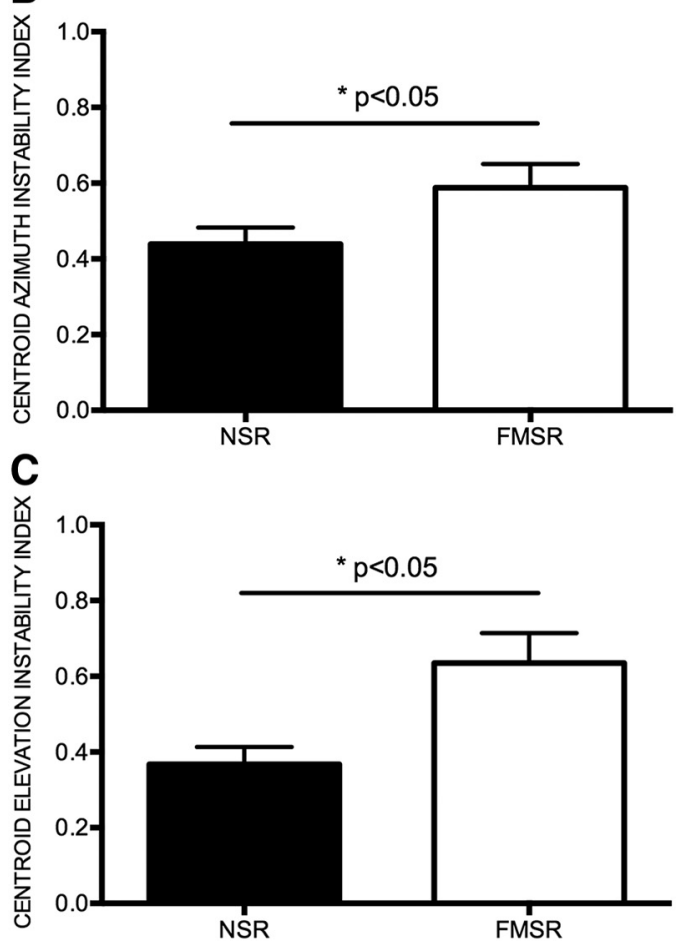

Figure 6. FMSR neurons were less level tolerant than NSR neurons. $\boldsymbol{A}$, The gyradius instability index indicates the extent to which the gyradius increased per decibel increase in SPL. $\boldsymbol{B}$, Centroid azimuth instability index shows the degree to which the centroid azimuth changed position per decibel increase in SPL.C, The centroid elevation instability index shows the degree to which the centroid elevation changed position per decibel increase in SPL. The $t$ tests revealed significant differences between the NSR and FMSR for all three measures.

The gyradius $R_{g}$ of the SRF was then given by the following:

$$
R_{g}=\sqrt{\frac{\sum \phi_{i}^{2} r_{i}}{\sum r_{i}}} .
$$

The $50 \%$ SRF is the contour within which the response of the neuron was $>50 \%$ of maximum response. The $50 \%$ SRF in azimuth (50\%SRF-AZ) and the $50 \%$ SRF in elevation (50\%SRF-EL) are the width of the $50 \%$ SRF at the centroid.

\section{Results}

Spatial receptive fields were recorded from 159 neurons in the pallid bat auditory cortex. Of these, 55 neurons were from the FMSR, and the remaining 104 neurons were from the NSR. SRFs were recorded with at least two different sound levels in 48 of 55 FMSR neurons and 81 of 104 NSR neurons. Figure 1 shows an example SRF of an NSR neuron to illustrate the various SRF properties quantified. Figure 2 shows SRFs of four representative
NSR neurons recorded at $10 \mathrm{~dB}$ (Fig. 2, left column) and $20 \mathrm{~dB}$ (Fig. 2, right column) above minimum threshold. These neurons serve to illustrate two consistent properties of NSR neurons. First, SRFs of NSR neurons were more selective for azimuth than elevation. Second, NSR neurons responded to a relatively contiguous region typically constrained to the CL space at both sound levels tested. Figure 3 shows three example SRFs from the FMSR that serve to illustrate the contrasting SRF properties between the two regions. SRFs of FMSR neurons occupied a contiguous and constrained region of space only at sound levels near threshold (Fig. 3, left column). At these intensities, SRFs were typically centered near the midline. A $10 \mathrm{~dB}$ increase in sound level results in an expansion of the SRF (Fig. $3 A-D$ ) or a fragmentation into multiple noncontiguous loci of strong responses (Fig. $3 E-H$ ).

These qualitative observations of contrasting NSR/FMSR SRFs were quantified by measuring gyradius, centroid, and $50 \%$ SRF. The azimuth and elevation range over which the response was within $50 \%$ of maximum (50\%SRF-AZ and $50 \%$ SRF-EL) at $20 \mathrm{~dB}$ above threshold was used to quantify the general shape of the SRF. Across the NSR population, SRFs were, on average, larger in elevation than in azimuth (Fig. 4; paired test, $p<0.0001$ ). It was not possible to perform this analysis for FMSR neurons because of the fragmented nature of the SRFs. Across the population, the centroid azimuths of the majority of NSR neurons were located in the CL hemifield (Fig. $5 A, B$, black bars). The centroid azimuths of NSR neurons collectively covered a broad region of the CL hemifield. The centroid elevations of most NSR neurons were distributed between $-10^{\circ}$ and $30^{\circ}$ elevation (Fig. $5 C, D$, black bars). As with the NSR neurons, the centroid azimuths of almost all of the FMSR neurons were located in the CL hemifield (Fig. $5 A, B$, white bars). However, unlike the NSR population that covered a broad range of azimuths, the centroid azimuths of the majority of FMSR neurons were located between midline and $20^{\circ}$ azimuth (Fig. 5). The distribution of centroid azimuths in the NSR and FMSR were significantly different from each other ( $\chi^{2}$ test, $p<0.0001$ at both sound levels). The distributions of centroid elevation were also significantly different between the two regions ( $\chi^{2}$ test, $p=0.003$ at $\mathrm{MT}+10$ $\mathrm{dB}$ SPL and $p=0.01$ at MT $+20 \mathrm{~dB}$ SPL) with the FMSR neurons being more tightly clustered near the midline compared with NSR neurons.

Comparison of centroid distribution within each region at the two different sound levels also reveals a difference between the NSR and FMSR. The distribution of centroid azimuths changes with sound level in the FMSR $\left(\chi^{2}\right.$ test, $\left.p<0.001\right)$, but not in the NSR ( $\chi^{2}$ test, $p=0.95$ ). The distributions of centroid elevations were not different at the two sound levels in either FMSR ( $\chi^{2}$ test, $\left.p=0.46\right)$ or NSR $\left(\chi^{2}\right.$ test, $\left.p=0.53\right)$. Together, these data indicate that the population of NSR neurons is collectively sensitive to a broad region of CL space. FMSR neurons are sensitive close to $0-20^{\circ}$ azimuth and elevation. The distributions of SRF centroid azimuths are level dependent in the FMSR, with a higher percentage of neurons preferring $0^{\circ}$ for the louder sound. The spatial selectivity of echolocation call selective neurons is thus focused on locations along the flight path from where echoes are expected. Given that the pallid bat hunts by localizing prey-generated noise, the sensitivity to a broader region of space in the NSR is likely an adaptation to the unpredictability of prey location in relation to the flight path of the bat.

The differential effect of sound level on centroid azimuth distributions in the two regions suggests that SRFs of individ- 

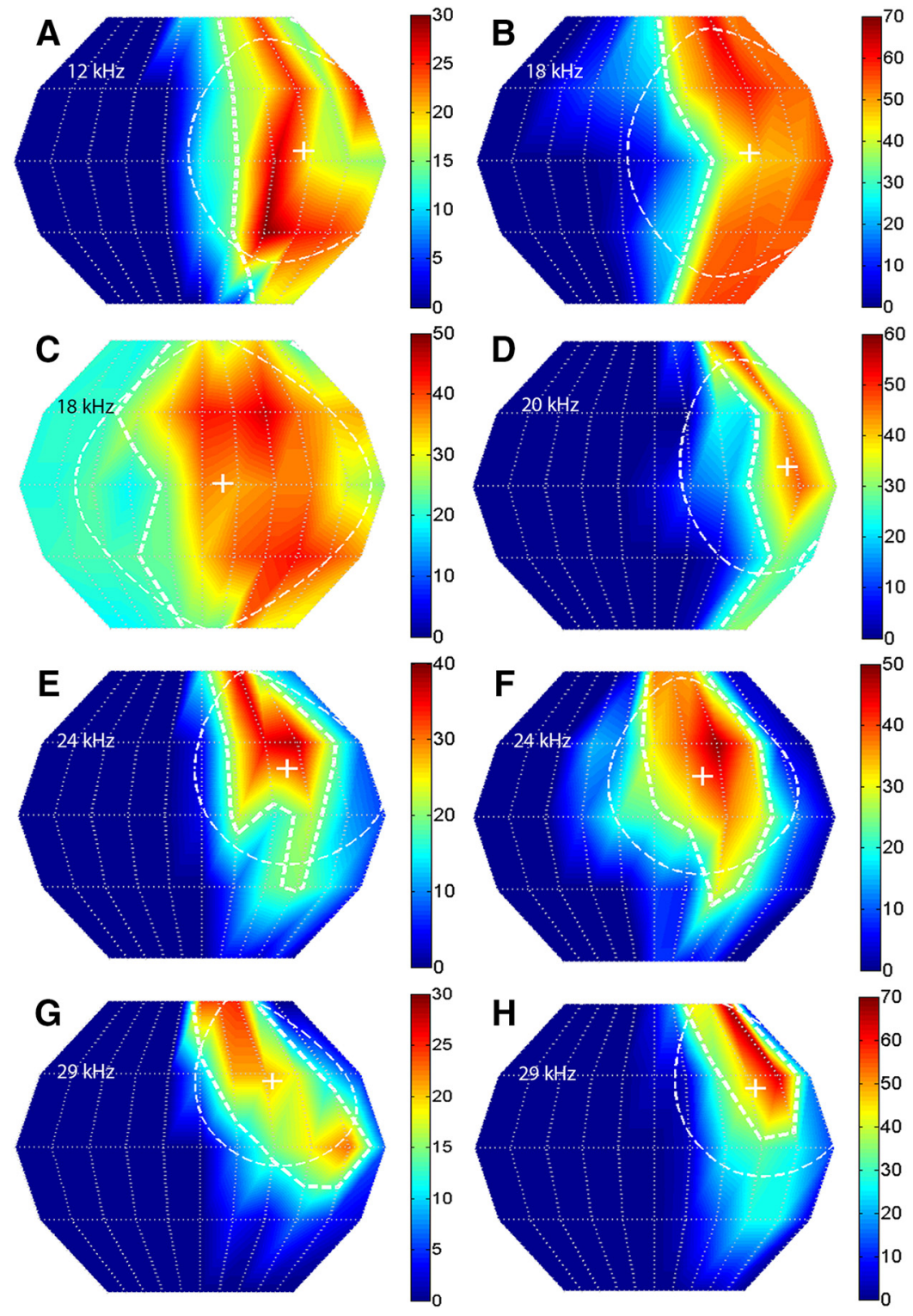

Figure 7. Relationship between CF and SRF properties in NSR neurons. SRFs of eight NSR neurons that exemplify the relationship between $C F$ and centroid elevation wherein the high-CF neurons have centroids at higher elevation. The gyradius, indicative of SRF size, also decreased with CF in these neurons. All SRFs were obtained with broadband noise at $20 \mathrm{~dB}$ above threshold. $\boldsymbol{A}$, Neuron \#87A01: $\mathrm{CF}=12 \mathrm{kHz}$, centroid azimuth $=42^{\circ}$, centroid elevation $=3^{\circ}$, gyradius $=47^{\circ} . B$, Neuron \#68B04: $\mathrm{CF}=18 \mathrm{kHz}$, centroid azimuth $=40^{\circ}$, centroid elevation $=3^{\circ}$, gyradius $=52^{\circ}$. C, Neuron \#93B03: $\mathrm{CF}=18 \mathrm{kHz}$, centroid azimuth $=9^{\circ}$, centroid elevation $=0^{\circ}$, gyradius $=61^{\circ}$. D , Neuron \#41B03: $\mathrm{CF}=20 \mathrm{kHz}$, centroid azimuth $=55^{\circ}$, centroid elevation $=8^{\circ}$, gyradius $=45^{\circ} . \boldsymbol{E}$, Neuron $\# 40 \mathrm{A01}: \mathrm{CF}=24 \mathrm{kHz}$, centroid azimuth $=37^{\circ}$, centroid elevation $=19^{\circ}$, gyradius $=40^{\circ}$. $\boldsymbol{F}$, Neuron $\# 34 \mathrm{A01}: \mathrm{CF}=24 \mathrm{kHz}$, centroid azimuth $=21^{\circ}$, centroid elevation $=17^{\circ}$, gyradius $=41^{\circ} . \mathbf{G}$, Neuron \#40B01: $\mathrm{CF}=29 \mathrm{kHz}$, centroid azimuth $=32^{\circ}$, centroid elevation $=27^{\circ}$, gyradius $=35^{\circ} . \boldsymbol{H}$, Neuron \#41A01: $\mathrm{CF}=29 \mathrm{kHz}$, centroid azimuth $=46^{\circ}$, centroid elevation $=24^{\circ}$, gyradius $=37^{\circ}$.

ual FMSR neurons are more level dependent than in the NSR. The example neurons in Figures 2 and 3 illustrate this to be the case, with FMSR neurons showing a constrained and contiguous SRF only at MT $+10 \mathrm{~dB}$ SPL and a larger (Fig. 3A-D) and/or fragmented (Fig. $3 E-H$ ) SRF at MT $+20 \mathrm{~dB}$ SPL. SRFs of the NSR neurons are similar at the two sound levels (Fig. 2). The gyradius instability index was calculated as the degree change in gyradius per decibel increase in sound level. A comparison between the NSR and FMSR neurons shows a significantly higher gyradius instability index in the latter (Fig. 6A; NSR, $0.38 \pm 0.04$; FMSR, $1.287 \pm 0.08 ; t$ test, $p<0.0001)$. The azimuth and elevation instability indices were also quantified

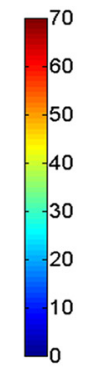

as the degree change in centroid azimuth and centroid elevation per decibel increase in sound level. Once again, the locations of centroid azimuth and elevation were more level dependent in the FMSR compared with the NSR (Fig. $6 B, C$; centroid azimuth instability index: FMSR, $0.59 \pm 0.06$; NSR, $0.43 \pm$ 0.04 ; centroid elevation instability index: FMSR, $0.64 \pm 0.07$; NSR, $0.37 \pm$ 0.04 ; $t$ test, $p<0.05$ ). Thus, SRFs were small at low sound levels in the FMSR neurons but show a considerable change in both SRF size and location of centroids with increasing sound levels. The SRFs were more stable in the NSR.

The centroid elevation and gyradius of NSR neurons were correlated with the CF. Figure 7 shows the SRF of eight NSR neurons recorded at $\mathrm{MT}+20 \mathrm{~dB}$ and arranged according to increasing $\mathrm{CF}$ (Fig. $7 A-H)$. As with the majority of NSR neurons (Fig. 5), these neurons were sensitive to the CL hemifield. The centroid elevation of these neurons systematically shifts upward with CF. Across the population, the centroid elevation of the SRF was correlated with CF in NSR neurons at both $\mathrm{MT}+10 \mathrm{~dB}$ (Fig. 8A) and MT + $20 \mathrm{~dB}$ (Fig. 8B). Low-CF NSR neurons exhibited lower centroid elevations compared with higher CF NSR neurons. There was no significant correlation between $\mathrm{CF}$ and centroid azimuth of NSR neurons (Fig. $8 C, D)$. This is consistent with previous studies that showed no relationship between CF and azimuth selectivity properties in the NSR (Razak, 2011, 2012). There was no correlation between CF and centroid elevation (Fig. 8E,F) or centroid azimuth (Fig. $8 G, H$ ) in the FMSR. Figure 7 also serves to illustrate that the higher $\mathrm{CF}$ neurons typically had smaller gyradii and thus were more elevation tuned (Fig. $7 F-H$ ). There was a significant correlation between the gyradius and the CF in the NSR at both sound levels tested (Fig. 9A,B). NSR neurons with lower CFs had a larger SRF compared with higher CF neurons. There was no significant correlation between CF and SRF gyradii in the FMSR (Fig. 9C,D). These data indicate a significant relationship between the elevation tuning and frequency tuning of a neuron in the NSR, but not in the FMSR.

\section{Discussion}

There were three major differences in the SRF properties of NSR and FMSR neurons. (1) Compared with NSR neurons, SRFs of FMSR neurons were more level dependent. (2) As a population, NSR neurons represent a broad region of contralateral space. FMSR spatial selectivity was focused near the midline at sound levels near threshold and show significant expansion and/or fragmentation with increasing levels. (3) The SRF size and centroid elevation were 

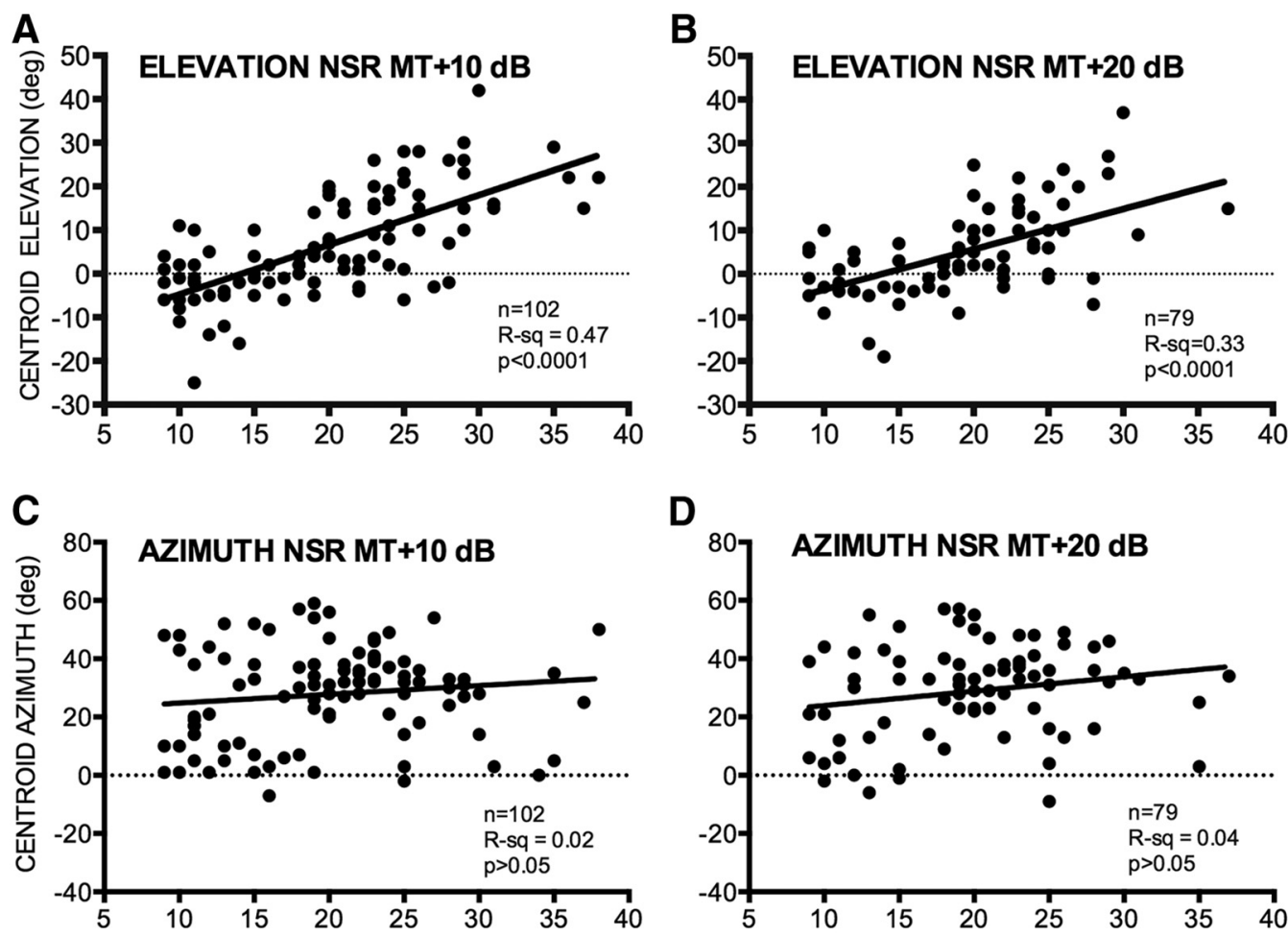

D
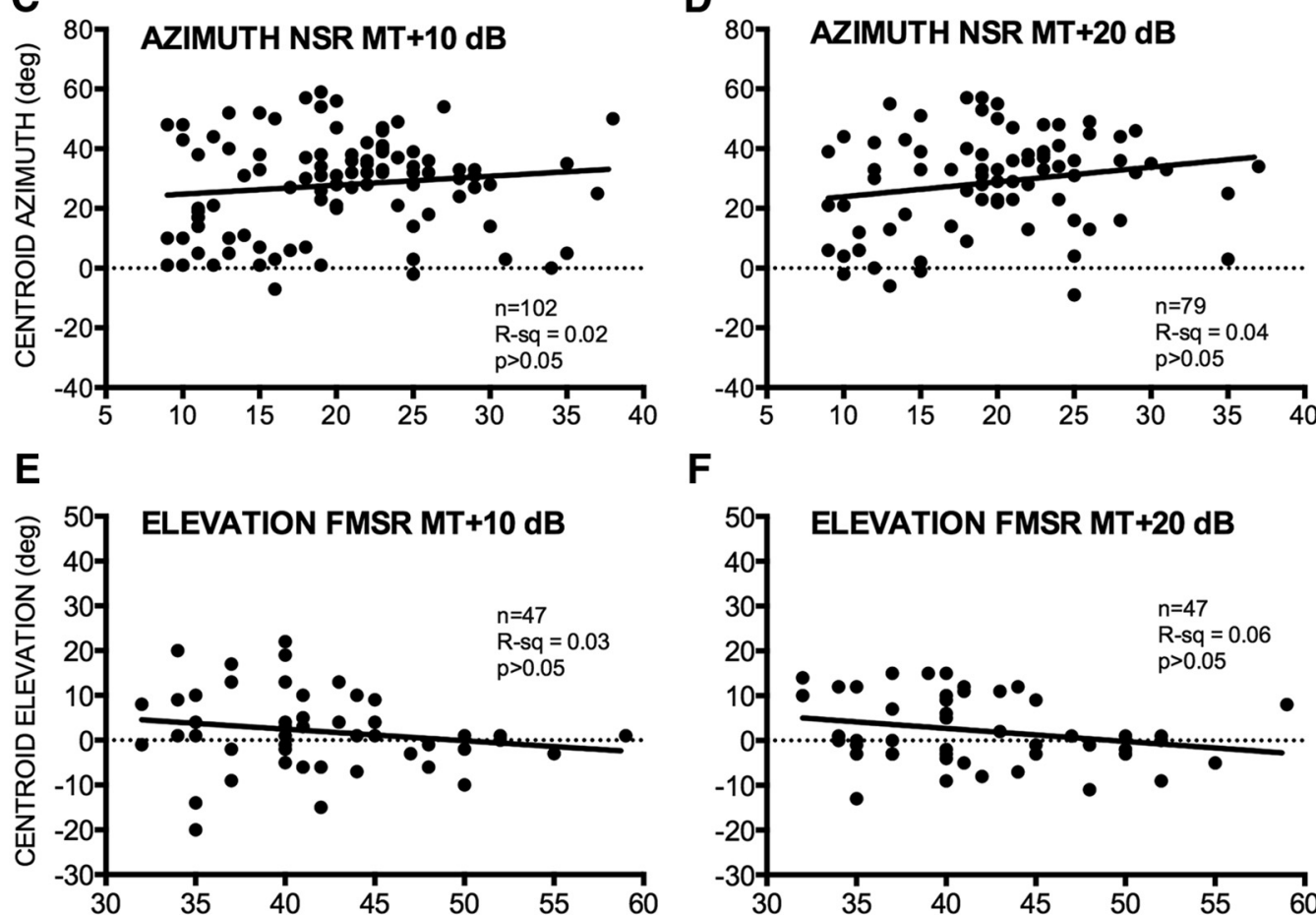

$\mathbf{F}$
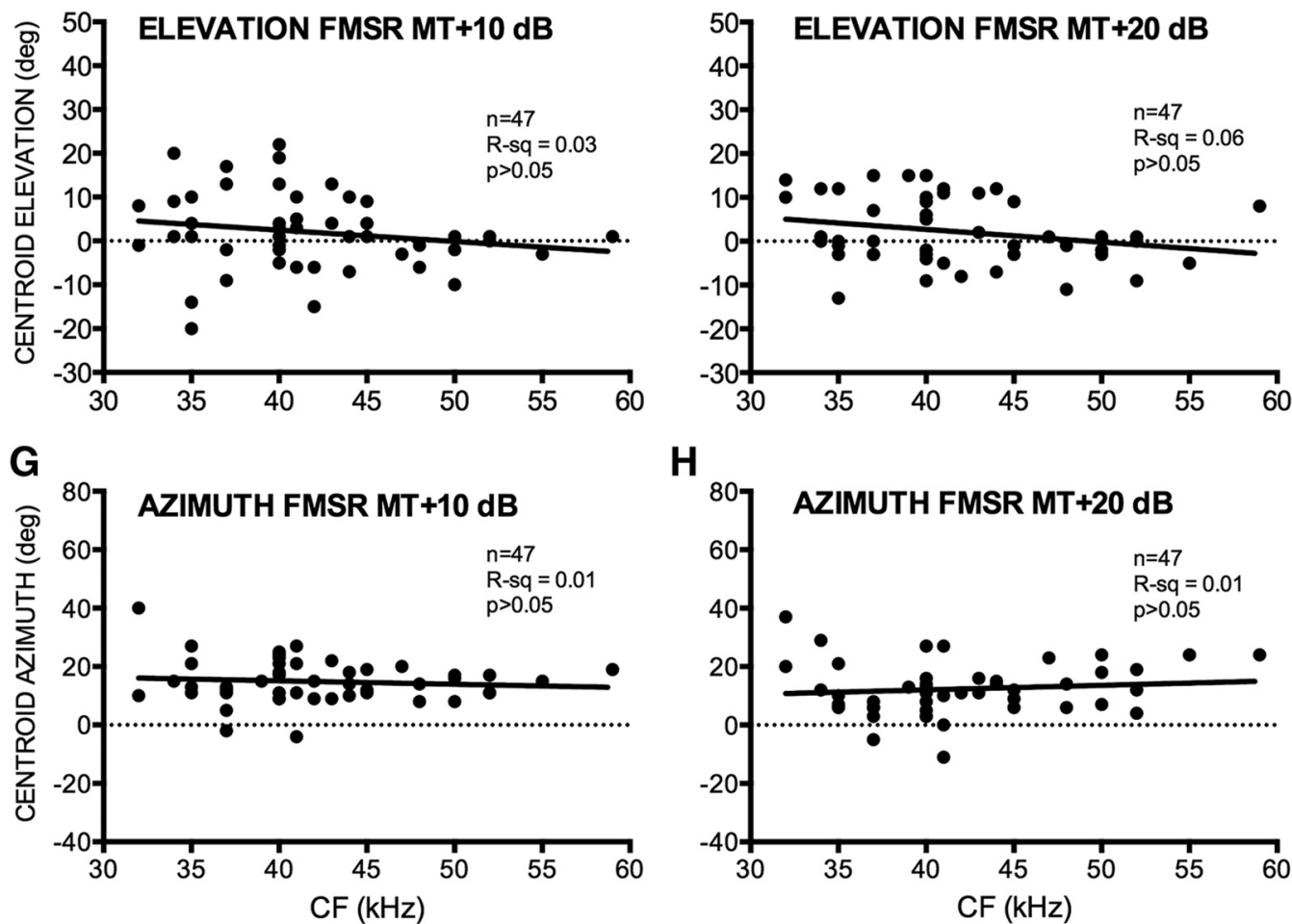

$\mathbf{H}$

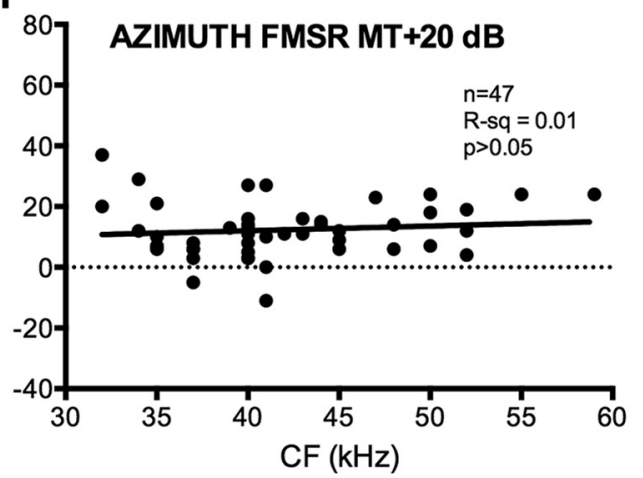

Figure 8. Relationship between CF and centroid azimuth or centroid elevation of NSR and FMSR neurons recorded at two different sound levels, MT $+10 \mathrm{~dB}$ (left column) and MT $+20 \mathrm{~dB}$ (right column). $\boldsymbol{A}, \boldsymbol{B}$, In NSR neurons, the CF and centroid elevation were significantly correlated at both sound levels. $C, \boldsymbol{D}$, In NSR neurons, no significant relationship was observed between CF and centroid azimuth. $\boldsymbol{E}-\boldsymbol{H}$, In FMSR neurons, no significant relationship was seen between $C F$ and centroid azimuth or elevation.

correlated with the CF in the NSR, but not in the FMSR. There was no correlation between centroid azimuth and CF in either region. These properties indicate that the cortical regions processing locations of prey-generated noise and echoes use different mechanisms of spatial representation, as discussed below.
A bicoordinate localization code in the NSR

The relationship among centroid elevation, SRF size, and CF in the NSR suggests a 2D localization code in the auditory cortex (Fig. 10). The EI cluster of the NSR contains a systematic map of ILD selectivity (Razak and Fuzessery, 2002). The ILD at which the 
A

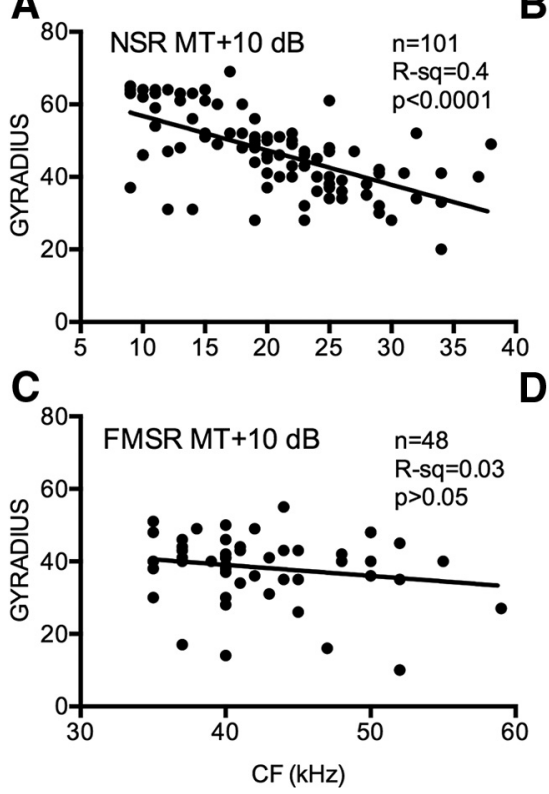

B
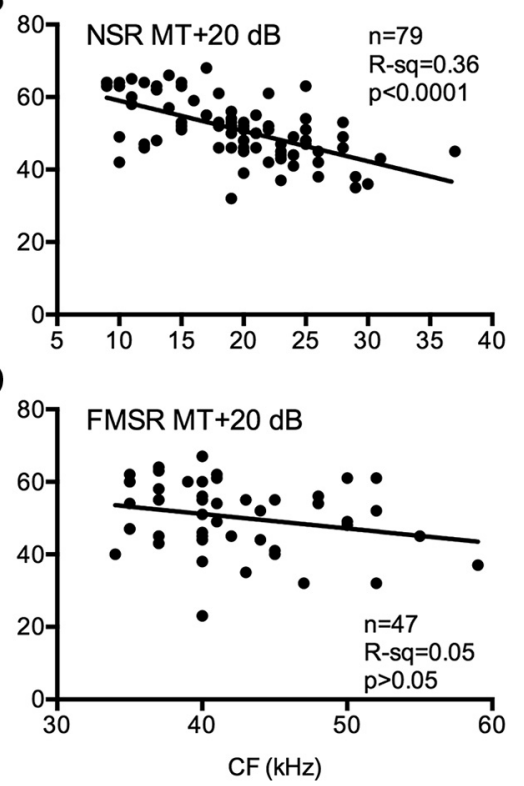

Figure 9. $\quad \boldsymbol{A}-\boldsymbol{D}$, Relationship between gyradii and CFs of $\operatorname{NSR}(\boldsymbol{A}, \boldsymbol{B})$ and $\operatorname{FMSR}(\boldsymbol{C}, \boldsymbol{D})$ neurons obtained at two different sound levels, $M T+10 \mathrm{~dB}$ (left column) and MT $+20 \mathrm{~dB}$ (right column).
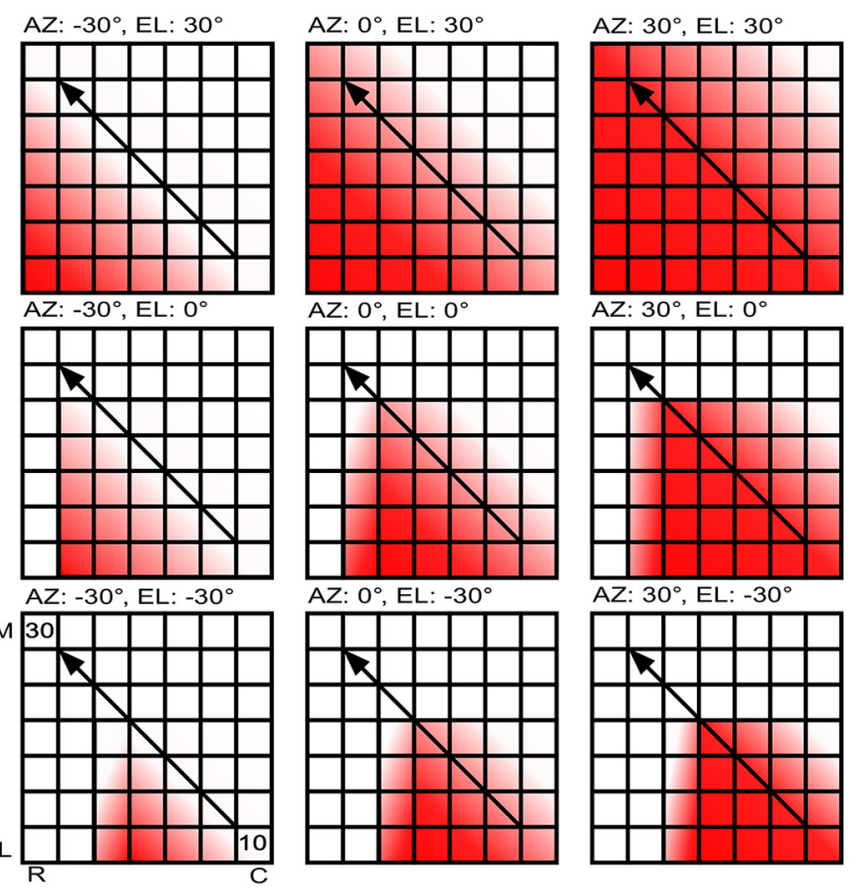

Figure 10. Schematic representation of how activity distribution in the NSR changes based on overlapping ILD and frequency maps, and the $2 \mathrm{D}$ location of a source generating broadband noise. Each panel shows the same cortical region but with activity patterns for specific $2 \mathrm{D} \mathrm{locations} \mathrm{in} \mathrm{space} \mathrm{(indicated} \mathrm{above} \mathrm{each} \mathrm{panel).} \mathrm{Sound} \mathrm{source} \mathrm{moves} \mathrm{from} \mathrm{IL} \mathrm{to} \mathrm{CL} \mathrm{space} \mathrm{in} \mathrm{the} \mathrm{left-column-}$ to-right-column direction and from low to high elevations in the bottom-row-to-top-row direction. Cortical orientation is provided in the bottom left panel. M, Medial; L, lateral; $R$, rostral; C, caudal. The color saturation scales with activity levels. The diagonal arrow indicates that the tonotopic direction in the NSR is in the caudolateral-to-rostromedial direction. See text for additional details.

response is inhibited to $50 \%$ of maximum response with increasing IL sound level [termed "inhibitory threshold" (IT)] is arranged systematically. Negative IT indicates that the neuron is inhibited only when the sound is louder in the IL ear. Positive IT indicates that the neuron is inhibited even when the IL sound level is lower than the CL sound level. Neurons with increasingly

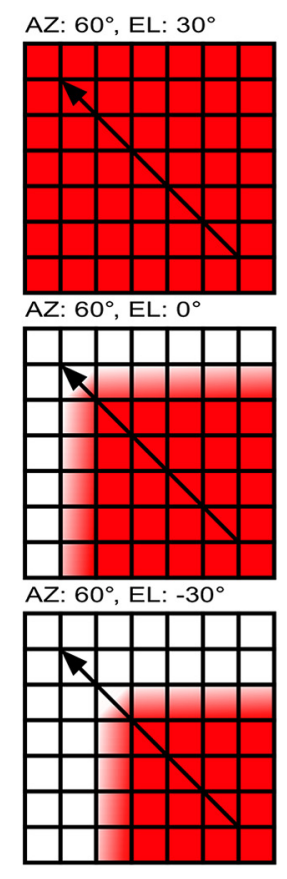

more negative ITs occupy more rostrolateral locations in the NSR (Razak, 2011). As a consequence of this arrangement of ITs, the movement of a source from IL to CL locations results in a systematic increase in the extent of activated cortex in a rostrolateral-caudomedial direction (Fig. 10). Thus, as in subcortical regions (Fuzessery et al., 1985; Wise and Irvine, 1985; McAlpine et al., 2001, Brand et al., 2002; Tollin et al., 2008), the binaural function slope provides the basis for a systematic azimuth-dependent distribution of population firing rates across cortex.

Data from the present study indicate that the azimuth-dependent extent of activated cortex will be further constrained by elevation-frequency interactions. Two relationships lead to this interpretation. First, the CF and centroid elevation of NSR neurons were correlated (higher CF neurons had higher centroid elevation; Fig. 8). Second, CF and gyradius were correlated (lower CF neurons had larger SRFs; Fig. 9). Characteristic frequencies in the NSR increase in a caudolateralrostromedial direction (Fig. 10, arrow), approximately orthogonal to the ILD map. For a broadband sound arriving from low elevations (e.g., $-30^{\circ}$; Fig. 10), the low-CF neurons will be activated more than the high-CF neurons ("elevation" describes vertical locations in relation to the head/snout direction). The ear directionality will also amplify low frequencies more than the high frequencies for low-elevation sources (Fuzessery, 1996). As the sound source rises in elevation, the ear will amplify higher-frequency sounds, and high-CF neurons will be recruited because of their sensitivity to higher elevations. This will occur without necessarily a loss of activity in low-CF neurons because these neurons have broad elevation tuning. The extent of NSR activity with changes in elevation will therefore be constrained by tonotopy (Fuzessery, 1986). As the sound source moves from IL to CL azimuth locations, more of the ILD map will be recruited. As the sound source rises from low to high elevations, more of the tonotopic map will be recruited. Thus, the overlap between the ILD and CF maps will dictate the overall extent of cortical activity for a given azimuth/elevation combination (Fig. 10). Conversely, the extent of activated cortex will change systematically with $2 \mathrm{D}$ source location.

The relationships observed between CF and SRF size/centroid elevation explain between $33 \%$ and $47 \%$ of SRF variance. Frequency tuning width, response latency, and sensitivity to spectral peaks/notches will additionally influence elevation encoding (Xu et al., 1998; Reale et al., 2003). The extent of NSR activity will 
remain relatively stable with sound level. One caveat is that there is a range of MTs in the EI cluster (30-60 dB SPL). A given sound level will stimulate different neurons at different levels above threshold. However, the overall pattern of EI activity spread is preserved even if the mapping is performed with a single sound level (Razak, 2011), because most EI neurons have monotonic rate-level responses and level tolerant ILD selectivity.

In addition to creating azimuth selectivity (Razak, 2012), ILD selectivity of NSR neurons is also predicted to shape the CFelevation tuning correlations observed here. In the pallid bat, for sounds with frequencies of $<20 \mathrm{kHz}$, the ILDs generated at a given azimuth are relatively elevation invariant (Fuzessery, 1996). This explains the broad elevation tuning at these frequencies. However, as frequencies increase between 20 and $35 \mathrm{kHz}$, the locations generating high ILDs become more constrained and shift to higher elevations. Thus, narrower elevation tuning and upper elevation centroids of high-CF NSR neurons (Figs. 2C,D, $7 E-H)$ arise due to the interactions among sound frequency, ear directionality, and ILD selectivity (Mrsic-Flogel et al. 2005).

The lack of a correlation between CF and centroid azimuth (Fig. 8C,D) or ILD/azimuth selectivity (Razak, 2011) indicates that frequency tuning does not influence horizontal localization. This is consistent with the notion that each isofrequency contour contains information to encode the CL azimuth in a frequencyspecific manner (Jenkins and Merzenich, 1984). The proposed code for elevation is consistent with how the spectral bandwidth of sounds influences elevation judgment (Blauert, 1969; Middlebrooks and Green, 1991; Populin and Yin, 1998). For example, gaze shifts by cats to elevation changes were more error prone when the high-frequency content of noise was filtered out (Tollin et al., 2013). The filtering removes mid-frequency spectral cues and prevents the full extent of the tonotopic map from being activated. Together, this reduces the ability to make acrossfrequency comparisons causing more errors in elevation judgment for narrowband noise.

\section{Spatial representation in the FMSR}

The FMSR region represents space differently than the NSR. The small SRFs near threshold and expansion with increasing sound levels simply reflect ear directionality at frequencies $>30 \mathrm{kHz}$ (Fuzessery, 1996). The majority ( $65 \%)$ of FMSR neurons are monaural (ILD insensitive) because only CL stimulation elicits a response with no IL ear influence, either monaurally or binaurally (Razak and Fuzessery, 2002). This explains the expansion of $\mathrm{SRF}$, at least in azimuth, with increasing levels. At higher sound levels, there is no binaural inhibition to restrict azimuth selectivity. Thus, unlike the NSR in which ILD/frequency selectivity shapes SRFs, FMSR neuron SRF is primarily shaped by monaural ear directionality.

The broad tuning and strong level dependence may suggest that the FMSR provides poor location information. FMSR neurons are selective for space only for low sound levels. For large obstacles, or when the bat is close to an obstacle, returning echoes will be relatively loud. Because the neurons are broadly tuned for louder sounds, a question arises as to how the bat accurately localizes the obstacle. The answer may lie in the fact that the pallid bat is a "whispering bat" (Griffin, 1958) that does not depend on loud echolocation calls to track small prey. The pallid bat also performs "intensity compensation," whereby the sound levels of the outgoing call are reduced if the returning echoes were loud (J. Barber, personal communication). The monaural FMSR neurons may be an adaptation for the bat to localize soft echoes with the resolution afforded by small SRFs while still being sensitive to the detection of louder echoes from a broader region of space. Thus, both detection and localization can be performed by actively controlling the sound level of the outgoing pulse. The FMSR will function at low sound levels under most echolocation tasks for which the 2D spatial selectivity of neurons is narrow and near the midline, along the flight path where most echoes will originate. The same FMSR neurons can detect closer and/or larger obstacles from a broader region of space to initiate appropriate avoidance behavior.

\section{Conclusions}

Parallel pathways are common in sensory systems. The data presented here show how response properties are shaped in different pathways to contribute to different functions. The cortical regions putatively involved in echolocation and prey localization represent 2D space differently, with the NSR depending on ILD and frequency selectivity, and the FMSR depending on monaural ear directionality (peripheral morphology). In the absence of a "one-to-one" space map in cortex, these data suggest a plausible mechanism for 2D spatial representation. The nature of overlap between frequency and ILD maps will restrict activity to relatively distinct cortical patches in a location-dependent fashion, thus providing a substrate for $2 \mathrm{D}$ location processing. The systematic ILD map is present within the cluster of EI neurons in the NSR (Razak, 2011), suggesting that high-density mapping of frequency and binaural selectivity within individual binaural clusters across species will inform about the generality of the proposed model. Future computational modeling will identify how the population activity distribution is read out (Miller and Recanzone, 2009). Behavioral studies are currently underway to test the predictions made by the model regarding bandwidth effects on 2D localization by the pallid bat.

\section{References}

Barber JR, Razak KA, Fuzessery ZM (2003) Can two streams of auditory information be processed simultaneously? Evidence from the gleaning bat Antrozous pallidus. J Comp Physiol A Neuroethol Sens Neural Behav Physiol 189:843-855. CrossRef Medline

Bell GP (1982) Behavioral and ecological aspects of gleaning by the desert insectivorous bat, Antrozous pallidus (Chiroptera: Vespertilionidae). Behav Ecol Sociobiol 10:217-223. CrossRef

Bizley JK, Nodal FR, Parsons CH, King AJ (2007) Role of auditory cortex in sound localization in the midsagittal plane. J Neurophysiol 98:1763-1774. CrossRef Medline

Blauert J (1969) Sound localization in the median plane. Acustica 22:205-213.

Brand A, Behrend O, Marquardt T, McAlpine D, Grothe B (2002) Precise inhibition is essential for microsecond interaural time difference coding. Nature 417:543-547. CrossRef Medline

Fuzessery ZM (1986) Speculations on the role of frequency in sound localization. Brain Behav Evol 28:95-108. CrossRef Medline

Fuzessery ZM (1994) Response selectivity for multiple dimensions of frequency sweeps in the pallid bat inferior colliculus. J Neurophysiol 72: 1061-1079. Medline

Fuzessery ZM (1996) Monaural and binaural spectral cues created by the external ears of the pallid bat. Hear Res 95:1-17. CrossRef Medline

Fuzessery ZM, Wenstrup JJ, Pollak GD (1985) A representation of horizontal sound location in the inferior colliculus of the mustache bat (Pteronotus p. parnellii). Hear Res 20:85-89. CrossRef Medline

Griffin DR (1958) Listening in the dark. New Haven, CT: Yale UP.

Heffner HE (1997) The role of macaque auditory cortex in sound localization. Acta Otolaryngol 532:22-27.

Holderied M, Korine C, Moritz T (2011) Hemprich's long-eared bat (Otonycteris hemprichii) as a predator of scorpions: whispering echolocation, passive gleaning and prey selection. J Comp Physiol A Neuroethol Sens Neural Behav Physiol 197:425-433. CrossRef Medline

Jenkins WM, Merzenich MM (1984) Role of cat primary auditory cortex for sound localization behavior. J Neurophysiol 52:819-847. Medline 
Kavanagh GL, Kelly JB (1987) Contribution of auditory cortex to sound localization by the ferret (Mustela putorius). J Neurophysiol 57:17461766. Medline

King AJ, Bajo VM, Bizley JK, Campbell RA, Nodal FR, Schulz AL, Schnupp JW (2007) Physiological and behavioral studies of spatial coding in the auditory cortex. Hear Res 229:106-115. CrossRef Medline

Malhotra S, Hall AJ, Lomber SG (2004) Cortical control of sound localization in the cat: unilateral cooling deactivation of 19 cerebral areas. J Neurophysiol 92:1625-1643. CrossRef Medline

Martin del Campo H, Measor K, Razak KA (2014) Parvalbumin and calbindin expression in parallel thalamocortical pathways in a gleaning bat, Antrozous pallidus. J Comp Neurol 522:2431-2445. CrossRef Medline

McAlpine D, Jiang D, Palmer AR (2001) A neural code for low-frequency sound localization in mammals. Nat Neurosci 4:396-401. CrossRef Medline

Middlebrooks JC, Green DM (1991) Sound localization by human listeners. Annu Rev Psychol 42:135-159. CrossRef Medline

Middlebrooks JC, Pettigrew JD (1981) Functional classes of neurons in primary auditory cortex of the cat distinguished by sensitivity to sound location. J Neurosci 1:107-120. Medline

Miller LM, Recanzone GH (2009) Populations of auditory cortical neurons can accurately encode acoustic space across stimulus intensity. Proc Natl Acad Sci U S A 106:5931-5935. CrossRef Medline

Mrsic-Flogel TD, King AJ, Schnupp JW (2005) Encoding of virtual acoustic space stimuli by neurons in ferret primary auditory cortex. J Neurophysiol 93:3489-3503. CrossRef Medline

Nakamoto KT, Zhang J, Kitzes LM (2004) Response patterns along an isofrequency contour in cat primary auditory cortex (AI) to stimuli varying in average and interaural levels. J Neurophysiol 91:118-135. Medline

O'Shea TJ, Vaughan TA (1977) Nocturnal and seasonal activities of the pallid bat, Antrozous pallidus. J Mammal 58:269-284. CrossRef

Populin LC, Yin TC (1998) Behavioral studies of sound localization in the cat. J Neurosci 18:2147-2160. Medline

Rajan R, Aitkin LM, Irvine DR (1990b) Azimuthal sensitivity of neurons in primary auditory cortex of cats. II. Organization along frequency-band strips. J Neurophysiol 64:888-902. Medline

Razak KA (2011) Systematic representation of sound locations in the primary auditory cortex. J Neurosci 31:13848-13859. CrossRef Medline

Razak KA (2012) Mechanisms underlying azimuth selectivity in the auditory cortex of the pallid bat. Hear Res 290:1-12. CrossRef Medline
Razak KA, Fuzessery ZM (2002) Functional organization of the pallid bat auditory cortex: emphasis on binaural organization. J Neurophysiol 87: 72-86. Medline

Razak KA, Fuzessery ZM (2006) Neural mechanisms underlying selectivity for the rate and direction of frequency-modulated sweeps in the auditory cortex of the pallid bat. J Neurophysiol 96:1303-1319. CrossRef Medline

Razak KA, Fuzessery ZM (2008) Facilitatory mechanisms underlying selectivity for frequency modulated sweeps in the auditory cortex. J Neurosci 28:9806-9816. CrossRef Medline

Razak KA and Fuzessery ZM (2009) GABA shapes selectivity for the rate and direction of frequency modulated sweeps in the auditory cortex. J Neurophysiol 102:1366-1378. CrossRef Medline

Razak KA, Fuzessery ZM (2010) GABA shapes a systematic map of binaural sensitivity in the auditory cortex. J Neurophysiol 104:517-528. CrossRef Medline

Razak KA, Shen W, Zumsteg T, Fuzessery ZM (2007) Parallel thalamocortical pathways for echolocation and passive sound localization in a gleaning bat, Antrozous pallidus. J Comp Neurol 500:322-338. CrossRef Medline

Reale RA, Jenison RL, Brugge JF (2003) Directional sensitivity of neurons in the primary auditory (AI) cortex: effects of sound-source intensity level. J Neurophysiol 89:1024-1038. CrossRef Medline

Stecker GC, Harrington IA, Middlebrooks JC (2005a) Location coding by opponent neural populations in the auditory cortex. PLoS Biol 3:e78. CrossRef Medline

Tollin DJ, Koka K, Tsai JJ (2008) Interaural level difference discrimination thresholds for single neurons in the lateral superior olive. J Neurosci 28:4848-4860. CrossRef Medline

Tollin DJ, Ruhland JL, Yin TC (2013) The role of spectral composition of sounds on the localization of sound sources by cats. J Neurophysiol 109: 1658-1668. CrossRef Medline

Whitfield IC, Cranford J, Ravizza R, Diamond IT (1972) Effects of unilateral ablation of auditory cortex in cat on complex sound localization. J Neurophysiol 35:718-731. Medline

Wise LZ, Irvine DR (1985) Topographic organization of interaural intensity difference sensitivity in deep layers of cat superior colliculus: implications for auditory spatial representation. J Neurophysiol 54:185-211. Medline

Xu L, Furukawa S, Middlebrooks JC (1998) Sensitivity to sound-source elevation in nontonotopic auditory cortex. J Neurophysiol 80:882-894. Medline 